\title{
EDITORIAL
}

Eloise Silveira Botelho

Universidade do Estado do Rio de Janeiro (UNIRIO),

Brasil

eloise.botelho@unirio.br

\author{
Carla Fraga \\ Universidade do Estado do Rio de Janeiro (UNIRIO), \\ Brasil \\ carlota.fraga@gmail.com \\ Simone Feigelson \\ Universidade do Estado do Rio de Janeiro (UNIRIO), \\ Brasil \\ vera.borges@unirio.br \\ Vera Borges \\ Universidade do Estado do Rio de Janeiro (UNIRIO), \\ Brasil \\ simone.feigelson@gmail.com
}

DOI: https://doi.org/10.18472/cvt.20n2.2020.1869 Redalyc: http://www.redalyc.org/articulo.oa? $\mathrm{id}=115464354010$

\section{PATRIMÔNIO E TURISMO: INTERFACES EM DEBATE}

O periódico Caderno Virtual de Turismo - Tempoespaço publica o dossiê "Patrimônio e Turismo: interfaces em debate", cujo objetivo é reunir reflexões em torno do patrimônio e turismo, e suas diversas interfaces, contribuindo para a reflexão sobre os temas: paisagem, urbanismo, mobilidades, ambiente, cidades, a partir de conhecimentos, métodos e práticas envolvendo pesquisa e extensão.

O presente dossiê é resultante de um conjunto de ações extensionistas e reflexões teóricas do Programa de Extensão "Metrópole Turismo debatendo Patrimônio" com a colaboração das professoras Eloise Botelho, Vera Borges, Carla Fraga e Simone Feigelson, do Departamento de Turismo e Patrimônio da Universidade Federal do Estado do Rio de Janeiro - UNIRIO, que tem como proposta a prática do turismo como um elemento gerador de renda e de inclusão social ao valorizar as tradições culturais, o patrimônio e a interação entre os residentes e os turistas por intermédio da mediação dos extensionistas.

É uma característica marcante do Programa o diálogo com pesquisadores extensionistas, a fim de construir e compartilhar conhecimentos teóricos e práticos sobre turismo e patrimônio no contexto das cidades. Com esta inspiração, o projeto "Turismo Cultural no Campo de Santana" é embrião da parceria, iniciada em 2014, com o Laboratório de Tecnologias, Diálogos e Sítios, coordenado pelo Prof. Roberto Bartholo (PEP/ COPPE/UFRJ), que coordenou o projeto "Janelas Abertas para a República" e que, atualmente, se amplia em diversas outras frentes acadêmicas.

Dentre as atividades propostas pelo Programa, em parceria com o "Grupo de Pesquisas Interdisciplinares em Turismo e Cidades" (INTERTUR) e o "Grupo de Pesquisa Transportes e o Turismo" (GPTT), ambos da UNIRIO, está a realização de eventos técnico-científicos como o "Colóquio Turismo e Cidades", o "Seminário Arquitetura, Urbanismo e Turismo - SAUT” e o Seminário "Metrópole, Turismo e Patrimônio - MEPAT”, como desdobramento e ampliação das ações de extensão, em interface com atividades de ensino e de pesquisa. Nessa amálgama, formada por temas interdisciplinares, o patrimônio cristaliza-se como 
centralidade dos questionamentos, debates, investigações e construção de saberes e práticas, reconhecendo a complexidade que o tema exige.

O presente dossiê é resultante das ações do Programa, e reúne trabalhos de vários pesquisadores de instituições brasileiras que, em diferentes edições dos eventos realizados, deram suas contribuições para as múltiplas noções do patrimônio e sua apropriação pelo turismo.

O artigo que abre o dossiê, intitulado "Turismo cultural no Campo de Santana e entorno: um estudo sobre a estação ferroviária Central do Brasil no Rio de Janeiro (RJ)", propõe uma conexão entre turismo, cultura e ferrovia para compreender a relação entre a Estação Central do Brasil e o jardim histórico do Campo de Santana, no Rio de Janeiro. A autoria é de Carla Fraga, Eloise Silveira Botelho, Simone Feigelson Deutsch e Vera Lúcia Bogéa Borges.

O artigo de autoria de Sênia Bastos nos presenteia com a problematização do processo de ressignificação do espaço e de expressóes culturais de etnicidade, com foco no bairro da Liberdade, em São Paulo - SP. A partir de uma perspectiva histórica, o artigo revela os ocultamentos e apagamentos desencadeados por esse processo, envolvendo as diferentes etnias que compóem a paisagem cultural.

Em seguida, o trabalho de autoria de Thiago Allis, Humberto Fois-Braga, Patrick Moratori e Carla Fraga, intitula-se "Turismo, Literatura e Tecnologias em Movimento". De cunho ensaístico, traz uma abordagem densa e inovadora sobre a interface patrimônio e turismo ao lançar questionamentos reflexivos sobre literatura, mobilidades, tecnologias e computação afetiva.

Dando sequência, "Desdobramentos do Processo de Patrimonialização da Paisagem Carioca na alimentação: o caso dos food trucks" é apresentado por Maria Amália Silva Alves de Oliveira e Gabriela Elis da Cunha. A partir de uma descrição de abordagem antropológica sobre a inserção dos food trucks no contexto dos eventos realizados na cidade do Rio de Janeiro, o trabalho contribui para o debate sobre os sentidos e significados culturais atribuídos ao alimento e ao ato de alimentar-se, com foco nas "cozinhas sobre rodas", em articulação com patrimônio e turismo.

Finalizando o dossiê, o artigo de Giovana Cioffi e Sidnei Raimundo, aborda, a partir de uma visão crítica, a evolução da relação conceitual entre "patrimônio" e "natureza", e analisa os paradigmas sob os quais assenta a noção de áreas protegidas. $\mathrm{O}$ trabalho intitulado "Áreas naturais protegidas: uma reflexão sobre a patrimonialização da natureza pela sociedade ocidental" contribui para iluminar o processo de institucionalização da natureza como patrimônio por meio da criação de áreas protegidas, ampliando o olhar sobre as relações sociais imbricadas neste processo.

Não se pode ignorar que, em 2020, o mundo é surpreendido com a grave crise sanitária resultante da pandemia da COVID-19, que exige novas reflexões e ações. Os trabalhos ora apresentados não negligenciam a relação pandemia, turismo e patrimônio, porém, em um emergente cenário ainda repleto de incertezas e dados em construção é pertinente o cuidado para conclusões científicas em bases sólidas. Este contexto, tão desafiador para o Programa de Extensão, nos convida para ações em novos formatos e reflexões. Assim, os eventos técnico-científicos II Seminário "Metrópole, Turismo e Patrimônio - MEPAT", IV Seminário “Arquitetura, Urbanismo e Turismo - SAUT” e VI "Colóquio Turismo e Cidades" ocorrerão, excepcionalmente, de forma conjunta, nos dias 03 a 06 de novembro de 2020, por vias remotas/on-line.

Neste momento importante em que o Caderno Virtual de Turismo - Tempoespaço reforça no seu escopo o interesse sobre a temática do Patrimônio, o presente dossiê espera ter contribuído para estimular a troca de experiências acadêmicas e o intercâmbio interinstitucional, a partir das diversas possibilidades de abordagens da interface turismo e patrimônio, visando a divulgação científica de resultante de projetos de pesquisa e extensão inovadores. 